\title{
A study of tropical tropopause using MST radar
}

\author{
K. Satheesan ${ }^{1, *}$ and B. V. Krishna Murthy ${ }^{2}$ \\ ${ }^{1}$ Department of Atmospheric Sciences, Cochin University of Science and Technology, Cochin, India \\ ${ }^{2}$ B1,Ceebros,47/20,IIIrd Main Road, Gandhinagar, Adyar, Chennai 600020, India \\ *now at: Meteorology and Oceanography Group, Space Applications Centre, Ahmedabad, 380015, India
}

Received: 10 June 2004 - Revised: 29 June 2005 - Accepted: 30 June 2005 - Published: 14 October 2005

\begin{abstract}
Using the MST radar data of vertical wind, the characteristics of the tropical tropopause, following four different definitions, depending on 1) temperature lapse rate, 2) cold point, 3) convective outflow and 4) potential temperature lapse rate minimum, are studied. From the vertical wind data of the radar, the altitude profiles of temperature and horizontal divergence are derived, from which the tropopause levels corresponding to i) the lapse rate ii) cold point iii) convective outflow level and iv) potential temperature lapse rate minimum are determined. The convective outflow level and hence the convective tropopause altitude is determined, for the first time using the MST radar data. The tropopause altitudes and temperatures obtained following the four definitions are compared on a day-to-day basis for the summer and winter seasons. Winter and summer differences in the tropopause altitude and temperature are also studied.
\end{abstract}

Keywords. Meteorology and atmospheric dynamics (convective process; middle atmosphere dynamics; tropical meteorology)

\section{Introduction}

In recent years, the tropical tropopause has become the focus of scientific interest spurred largely by a realization that the tropics hold the key to the variability in global climate. The tropopause, which demarcates the troposphere and stratosphere, can be considered to be the region of transition between radiative-convective equilibrium and radiative equilibrium. Its most fundamental characteristic is a change in static stability and the associated change in vertical mixing time scales (Holton et al., 1995). The tropical tropopause region is important as the source region for much of the air entering the stratosphere (e.g., Holton et al., 1995). The mean heat balance of the troposphere is considered to be between convective heating (through the sensible heat flux from the surface and latent heat released during precipitation/by con-

Correspondence to: B. V. Krishna Murthy

(bvkmurthy2@rediffmail.com) vective clouds) and cooling by radiation from water vapour. Thus, radiative cooling is an important constraint on convection (Hartman and Larson, 2002). This implies that the most active convection will be limited to the altitude range where radiative cooling is efficient. The peak in detrainment of convection occurs at the level of maximum mass divergence. This detrainment and divergence (maximum) occur well below the tropopause, as defined by the level of minimum temperature (cold point), and do not appear to be caused in any direct way by lapse rate changes (Hartman and Larson, 2002). The level of maximum divergence can be taken to represent the tropopause level corresponding to the top of convection. Although most convection is generally thought to detrain below the $\sim 150 \mathrm{hPa}$ level, it can penetrate to higher levels and sometimes even above the level of cold point in temperature, especially during strong deep convection events. The fact that temperatures in the lower and middle (tropical) troposphere are governed mainly by convection is borne out by the lapse rates which are close to moist adiabatic. The lapse rates deviate from that of the moist adiabat in the upper troposphere (Sherwood et al., 2003). In fact, simple models suggested that the cold point in the temperature profile is actually a stratospheric feature which does not depend upon convection, owing its existence mainly to the photochemical production of ozone near the $100 \mathrm{hPa}$ level (Kirk-Davidoff et al., 1999; Thuburn and Craig, 2002). On the basis of the simple picture of the tropopause, that it represents the cap imposed on tropospheric convection by the stably stratified inversion layer of the stratosphere, the potential temperature of the air at the tropopause is expected to be roughly equal to the equivalent potential temperature of the boundary layer air (Reid and Gage, 1981). However, the tropopause (defined by minimum temperature) potential temperature is nearly always higher than the boundary layer air equivalent potential temperature. This additional heating is higher in northern winter and smaller in summer (Reid and Gage, 1996). This additional heating can come from i) episodic Rossby-wave activity in the Northern Hemisphere (from extra tropical region), injecting ozone rich stratospheric air directly along isentropic surfaces into 
the tropical upper troposphere and ii) stronger tropical tropospheric convective activity, leading to increased penetration of tropospheric air into lower stratosphere and entraining ozone-rich stratospheric air into the upper troposphere as it settles down to its equilibrium level (Reid and Gage, 1996). Which of these two is dominant and in which season are questions that remain unanswered. At any rate, it appears that the large 'scale suction pump' driven by extra tropical wave activity and strong tropospheric convection are the two dominant processes playing key roles in governing the tropical tropopause. It is clear that the tropical tropopause is not a fixed material surface but rather is a region of transition from convective to radiative equilibrium (Holton et al., 1995). Gettelman and Forster (2002) suggested that the tropical tropopause can be considered as a layer of transition between the convectively dominated troposphere and the radiatively controlled stratosphere.

Complete knowledge of the tropical tropopause characteristics is essential to the understanding of the physical processes in the tropical tropopause region. Part of the difficulty for this is in making observations at the required spatial and temporal scales. The Mesosphere Stratosphere Troposphere (MST) radar provides vertical wind data from which temperature can be obtained with good altitude resolution, giving a means to study the tropical tropopause characteristics albeit only at a few spot locations.

There are mainly four different ways of identifying the tropical tropopause (Highwood and Hoskins, 1998). These are:

1. The lapse rate tropopause (LRT) is defined as the lowest altitude (in the troposphere) at which the temperature lapse rate decreases to $2 \mathrm{~K} / \mathrm{km}$ or less and the lapse rate averaged between this altitude and any altitude within the next $2 \mathrm{~km}$ does not exceed $2 \mathrm{~K} / \mathrm{km}$. This definition mainly serves the operational purpose and has limited physical relevance (Highwood and Hoskins, 1998). There seems to be little direct connection between convective processes and LRT.

2. The tropical tropopause can be identified as the altitude at which the temperature is minimum and this is called the cold point tropopause (CPT). This is quite relevant in the transport of minor species, especially water vapor and is deemed important for stratosphere-troposphere exchange by Selkirk (1993).

3. The level of the top of nearly all the convection is a physically meaningful definition of the tropopause. The tropopause is considered to be at the top of the convective region and the region above this is assumed to be mainly in radiative equilibrium (Highwood and Hoskins, 1998). This is also the level of maximum horizontal divergence (Gettelman and Forster, 2002). This level is the level of where convective outflow occurs at a lower level compared to LRT and CPT.

4. Gettelman and Forster (2002) regarded the altitude of minimum lapse rate as a good marker of the level where radiation begins to influence the temperature profile as it departs from a saturated moist adiabat. They considered it physically more meaningful to consider a tropical tropopause layer, TTL, as a transition layer between the convectively dominated tropical troposphere and the radiatively controlled stratosphere. Thus, LRM/top of the convective outflow level is considered as the base of TTL and CPT as its upper boundary. Besides these four definitions, tropopause can be identified depending upon potential vorticity. However, this is more appropriate for defining the extra tropical tropopause which is considered as representative of the surface of constant potential vorticity (Holton et al., 1995).

We have carried out investigations on the tropical tropopause using the data from MST radar at Gadanki $\left(13.5^{\circ} \mathrm{N}, 79.2^{\circ} \mathrm{E}\right)$, a tropical station, following the four definitions mentioned above, and the results of these are described in this paper. Only data from the MST radar have been used to obtain the altitude and temperature of the tropopause, following the four definitions of tropopause given above. It may be mentioned here that stable layers giving rise to increased return signal strength have been identified around the tropopause (using LRT definition), using MST radar (e.g., Gage et al., 1986; Jain et al., 1994). These stable layers have been found to be associated with temperature inversion near the tropopause (LRT) level (Jain et al., 1994). In the present study we have not considered these stable layers in studying the tropopause behaviour, as it is a separate study by itself and is beyond the scope of the present study.

\section{Data and analysis}

The vertical wind data obtained from the MST radar at Gadanki is used in the present study. A detailed description of the MST radar at Gadanki is given by Rao et al. (1995). Vertical wind data was collected from the radar for a duration of two hours (from 20:00 to 22:00 IST) at $\sim 40$ s intervals on all the days during 18 January-5 March 1999 (winter 1999), 21 February-1 April 2000 (winter 2000), 2 July13 August 2001 (summer 2001) and 4 February-20 March 2002 (winter 2002). Altitude profiles of temperature have been derived from MST radar data of vertical wind on all the days of data collection, following the method of Revathy et al. $(1996,1998 \mathrm{a})$. The method involves identification of the Brunt-Väisälä frequency $(N)$ from the temporal spectrum of the vertical wind. From the altitude profile of $N$, the altitude profile of temperature is obtained by integration using the surface temperature as the boundary value (Revathy et al., 1996). The method is applicable only under convectively stable conditions, i.e., when $N^{2}$ is positive. When the background wind speed (horizontal) is high $(\gtrsim 40 \mathrm{~m} / \mathrm{s})$, identification of $N$ from the vertical wind temporal spectra may become difficult due to Doppler shifting of the lower frequency gravity waves. However, occurrences of such high horizontal velocities (in the troposphere and lower stratosphere) were 
rather rare, especially in winter, and at any rate, such data are not considered in the present study.

The errors in the determination of temperature profile by the method of Revathy et al. (1996) have been estimated by Revathy et al. (1998b). The errors arise mainly due to the errors in the estimation of $N$ and in the boundary value of temperature. The standard deviations of the temperature are estimated to be typically $0.7 \mathrm{~K}, 1.2 \mathrm{~K}$ and $1.6 \mathrm{~K}$ at altitudes $6.75 \mathrm{~km}, 14.25 \mathrm{~km}$ and $20.25 \mathrm{~km}$, respectively, for an altitude resolution of $150 \mathrm{~m}$. A detailed comparison of the temperature profiles obtained by this method (from MST radar) with those from radiosonde has been done (Mohan et al., 2001). The agreement between the two was found to be fairly good, especially on clear sky days. In the present analysis, in the three winter seasons only clear skies were encountered during the observation period (20:00 to 22:00 IST) on all the days. In the summer seasons there were a couple of days with cloudy skies (during the observation period) which were not included in the analysis. It may be noted here that the method of Revathy et al. (1996) has been successfully used for the studies on the diurnal variation of troposphere temperatures and equatorial waves (Revathy et al., 2001; Krishna Murthy et al., 2002). The temperature profiles thus obtained and the vertical wind profiles (from MST radar) form the basic data for obtaining the tropopause altitude (and temperature), according to its definitions given above.

\subsection{Determination of lapse rate tropopause (LRT)}

The altitude profile of the temperature lapse rate is obtained for each of the temperature profiles. From this, the tropopause altitude is identified as per the definition given in Sect. 1 and the temperature of that altitude is noted. The LRT altitude and temperature are designated by $H_{L R}$ and $T_{L R}$, respectively.

\subsection{Determination of cold point tropopause (CPT)}

The altitude profiles of temperature are smoothed by a 5point running mean filter, as it is found that fluctuations are superposed on some of the profiles. The smoothing facilitates identification of temperature minimum, which is identified from the smoothed profile, and the corresponding altitude and temperature are noted. These are designated as $H_{C P}$ and $T_{C P}$, respectively.

2.3 Determination of tropopause altitude corresponding to the level of convective outflow

In order to identify the level of convective outflow, the vertical wind observations sampled at $\sim 40 \mathrm{~s}$ intervals for a duration of two hours on all days of MST radar observations are used. The convective outflow level is the level of maximum horizontal divergence (Highwood and Hoskins, 1998). This can be obtained by considering the continuity equation given by

$\frac{\partial \rho}{\partial t}+\nabla \cdot(\rho \boldsymbol{U})=0$ where $\rho$ is the atmospheric density and $\boldsymbol{U}$ is the wind vector. The local rate of change of density and the horizontal advection terms in Eq. (1) can be considered to be generally small in comparison with the other terms in the equation, except perhaps during strong convection events. During the data collection periods in this study mentioned above, no strong convection events occurred. Thus, neglecting the $\partial \rho / \partial t$, the local rate of change of density and the horizontal advection term in Eq. (1) $u \partial \rho / \partial x+v \partial \rho / \partial y$ as zero, Eq. (1) can be written as

$$
\begin{aligned}
\frac{\partial u}{\partial x} & +\frac{\partial v}{\partial y}=-\left[w \frac{\partial \rho}{\partial z}+\rho \frac{\partial w}{\partial z}\right] \frac{1}{\rho} \\
& =\left[-\frac{w}{\rho} \frac{\partial \rho}{\partial z}-\frac{\partial w}{\partial z}\right]=D \text { (say). }
\end{aligned}
$$

From the hydrostatic equation,

$\frac{1}{\rho} \frac{\partial \rho}{\partial z}=-\frac{1}{H}$,

where $H$ is the scale height given by $H=k T / m g$, where $k$ is the Boltzmann's constant, $T$ is the temperature, $m$ is the mean molecular mass and $g$ is the acceleration due to gravity. Thus

$D=\left[\frac{w}{H}-\frac{\partial w}{\partial z}\right]$.

The positive value of $D$ represents horizontal divergence and the negative value represents convergence.

The altitude profiles of the vertical wind $\mathrm{w}$ are averaged over the 2-h period to give an average profile of $w$ on all the days of observations. These average profile values of vertical wind are used in Eq. (5) to calculate $D . H$ is obtained using the temperature profile (which also corresponds to the vertical wind data period of $2 \mathrm{~h}$ ) obtained from vertical wind observations as described earlier. Mean molecular mass is taken as 29 in calculating $H$.

It may be mentioned that the assumption of hydrostatic equilibrium implies neglect of flow acceleration that may not be strictly valid. As $H$ is calculated at height intervals of $150 \mathrm{~m}$ (using the temperature data of MST radar), this approximation may be taken, to hold good, at the time scales involved in the present studies, i.e. two hours.

The altitude profiles of $D$ obtained as described above are subjected to a 9-point running mean filter to smooth the profiles. The running mean profiles of $D$ are presented in Fig. 1 for two days as typical examples along with the standard errors. The altitude of the divergence peak (convective outflow level) at the highest altitude below $H_{C P}$ is taken as the level of the top of all convective outflow, to represent the convective tropopause, and is indicated by an arrow in this figure. It may be noted that there are convective outflows below this level (Fig. 1) and the topmost of these occurring below $H_{C P}$ is taken as the top of all convective outflow. It is generally observed that convective outflow, as represented by values of horizontal divergence, $D$, is stronger in summer compared to winter. Further, it has been observed that the level of convective outflow is more marked in summer than in winter, 

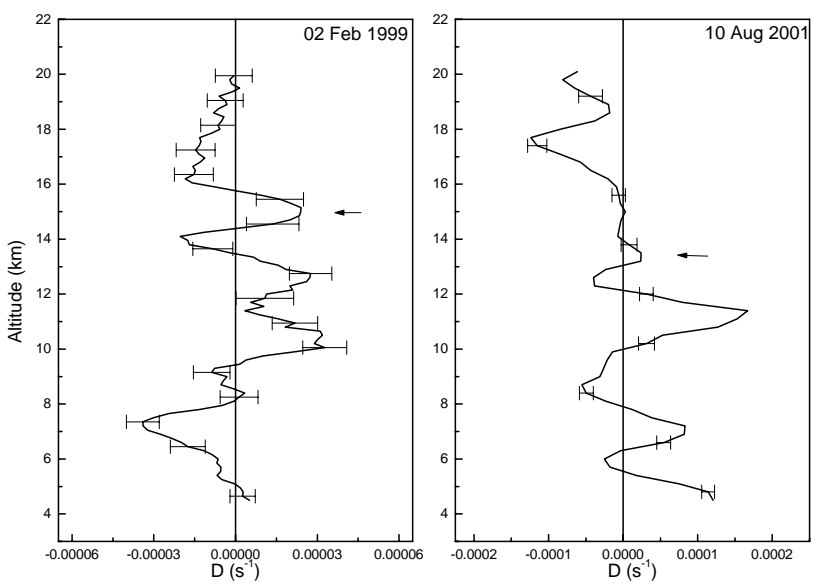

Fig. 1. Altitude profiles of $D$ for 2 February 1999 and 10 August 2001.
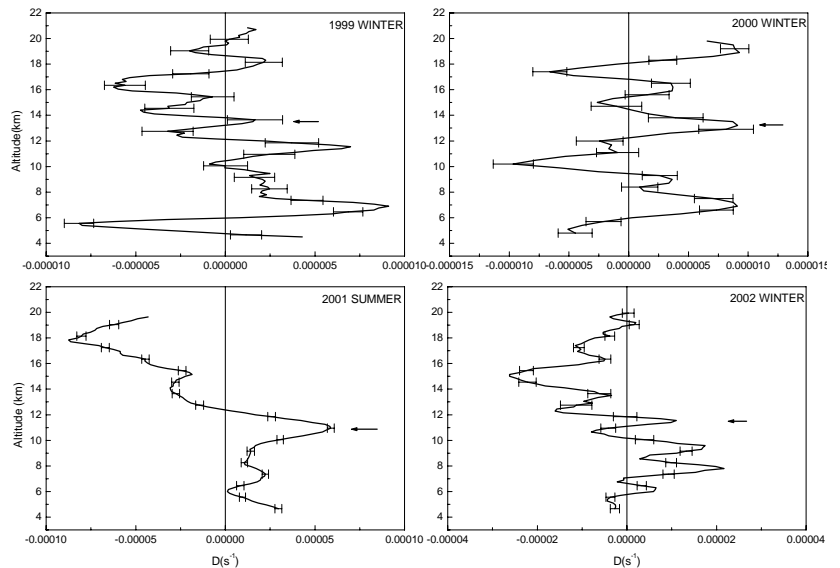

Fig. 2. Seasonal average profiles of $D$ for winter 1999, winter 2000, summer 2001 and winter 2002.

in general. It may be noted that the summer season (JulyAugust) is also the period of southwest monsoon over India when strong convection would prevail.

The seasonal average profiles of $D$ (obtained from its running mean profiles), along with the standard errors for the four seasons, are depicted in Fig. 2. The convective outflow level is marked by the horizontal arrow. The maximum positive $D$ value is much greater in summer than in winter, indicating that the convective outflow is much stronger in summer (monsoon) than in winter. This is not surprising, as strong convection is expected in the summer (monsoon) months. The altitude of the top of the convective outflow (in the troposphere) in summer is lower than in winter, where there is more than one prominent convective outflow level in the troposphere. In fact, the convective outflow (as indicated by the $D$ value) is stronger at the lower levels than at the top of the convective outflow in the troposphere, especially in winter 1999 and 2002. Further, convective outflow is seen even at lower stratospheric altitudes in winter especially in the years 1999 and 2000, which is not seen in summer. Thus, it appears that convection can penetrate into the lower stratosphere in winter. It is also seen that there is significant convergence above the convective outflow level (in the troposphere), both in winter and summer. A prominent feature in the summer average profile of $D$ is the convergence peak (negative $D$ ) at $\sim 18 \mathrm{~km}$ around the cold point tropopause level. Strong convection (as in summer) is expected to be accompanied by diabatic cooling at higher levels, leading to convergence (Salby et al., 2003).

It is interesting to note here that Gettelman et al. (2002), from a global analysis of convective cloud observed that convection above the tropopause is high in the Northern Hemisphere in winter and particularly over the Indian summer monsoon region. The present study uses data at a single station, using MST radar data and reveals that convection, though weak in winter, penetrates into the lower stratosphere and while in summer though convection is strong, it is confined to the troposphere and does not penetrate into the lower stratosphere. Recently, it has been shown that extra tropical wave driving, which is stronger in the northern hemispheric winter, contributes to the tropical tropospheric upward flow, (Holton et al., 1995). From the present study, it appears that the tropospheric upward flow leading to horizontal divergence in winter, driven mainly by the extra tropical waves, penetrates into the lower stratosphere, whereas the relatively stronger horizontal divergence in summer, driven mainly by the local convection, is confined to tropospheric altitudes. These studies should be extended with a larger database and at more locations using radar which gives more reliable and direct information on convection than the indirect methods using the satellite-based cloud cover and Outgoing Long wave Radiation (OLR) data. Gettelman and Forster (2002) pointed out the uncertainties in obtaining convection information using cloud cover and OLR data. The radar method has the advantage (over the one using satellite data) of identifying the convective outflow level even under conditions of dry convection.

From the altitude profiles of $D$, the level of maximum divergence is identified as described above. This level is taken as the tropopause corresponding to the convective outflow and its altitude and temperature, as $H_{C O}$ and $T_{C O}$, are obtained.

It should be pointed out here that as the vertical wind profiles are averaged over $2 \mathrm{~h}$ for the estimation of $D$, gravity wave effects corresponding to periods less than or equal to $2 \mathrm{~h}$, if any, on the vertical wind profiles would be smoothed out. In order to examine further the possibility that the fluctuations with altitude in the $D$ profiles could be manifestations of gravity waves, the correlations between the vertical wind profiles(from which $D$ are obtained) and the corresponding profiles of zonal and meridional wind (obtained from the MST radar observations) have been estimated and are found to be insignificant. If the fluctuations (in the $D$ profiles) are due to gravity wave effects, then the horizontal and vertical wind components would be correlated. As it is found this is not so; it is unlikely that the fluctuations in the $D$ profiles are 
due to gravity waves. At any rate, the gravity wave amplitudes, in general, are expected to be quite small in the troposphere (and lower stratosphere), whereas the fluctuations in the $D$ profiles are quite large. Furthermore, the seasonal average profiles involved averaging of profiles of $\sim 40$ days and so any effect of gravity waves will be smoothed out, as gravity wave fluctuations are not expected to any correspond from day-to-day. From the above, the gravity wave effects, if any, on the $D$ profiles can be considered to be insignificant and the $D$ profiles can be taken to represent convergence/divergence effects.

It should be mentioned here that as the temperature profile is derived from the Brunt-Väisälä frequency $(N)$ obtained from the vertical wind profile, thermally (convectively) stable conditions prevailed only on time scales corresponding to $N$ (of the order of $\sim 10 \mathrm{~min}$ ). Convection on longer time scales can still take place. As the vertical wind data, used for the estimation of $D$ in the present study, are averaged over a period of $2 \mathrm{~h}$, it represents convection over the corresponding time scales. Thus, the $D$ profiles can be considered to represent convergence/ divergence on time scales of $\sim 2 \mathrm{~h}$. Use of vertical wind data over longer periods would certainly yield information on convergence/divergence and hence on the convective outflow level on longer time scales. In the present work, it is demonstrated that MST radar data of the vertical wind can indeed be used to obtain the convective outflow level (on $\sim 2 \mathrm{~h}$ scales). Radars operating at a few $\mathrm{cm}$ wave lengths have been used in the past to study deep convection, particularly the events associated with precipitation (Mapes and Houze, 1993, 1995). Mapes and Houze (1995) studied mesoscale convection systems and the convergence/divergence associated with convective storms. They had shown that systematic differences exist in the convergence/divergence profiles between stratiform and convective precipitation. All these studies pertain to major convection (storm) events. In the present study period, there were no occurrences of strong convective events in the winter seasons and there were a couple of events in summer which are not included in the analysis. It would be of interest to compare the divergence/convergence profiles obtained by MST radar with those from a colocated $\mathrm{cm}$ wavelength radar during strong convective storm events.

\subsection{Determination of lapse rate minimum tropopause}

The altitude profile of potential temperature $(\theta)$ is obtained from that of the temperature. The required altitude profile of pressure is obtained using the hydrostatic equation and the temperature profile. From the altitude profile of $\theta$, the lapse rate $\left(-\frac{\partial \theta}{\partial z}\right)$ profile is obtained and its minimum is identified, which is taken as the level of lapse rate minimum tropopause.

\section{Day-to-day variations of tropopause altitude and tem- perature}

The daily values of the tropopause altitude obtained as described earlier are plotted for the four seasons against the day
Table 1. The seasonal average tropopause altitudes (in $\mathrm{km}$ ) and temperatures (in $\mathrm{K}$ ). The values inside the brackets are the standard errors.

\begin{tabular}{lrrrr}
\hline & $\begin{array}{r}1999 \\
\text { Winter }\end{array}$ & $\begin{array}{r}2000 \\
\text { Winter }\end{array}$ & $\begin{array}{r}2001 \\
\text { Summer }\end{array}$ & $\begin{array}{r}2002 \\
\text { Winter }\end{array}$ \\
\hline $\bar{T}_{C P}$ & $196.5(0.61)$ & $203.4(1.15)$ & $194.9(1.36)$ & $190.7(1.14)$ \\
$\bar{T}_{\theta M}$ & $210.7(0.99)$ & $214.8(1.32)$ & $199.9(1.75)$ & $198.5(1.67)$ \\
$\bar{T}_{L R}$ & $201.9(0.90)$ & $204.3(1.09)$ & $196.8(1.00)$ & $194.5(1.46)$ \\
$\bar{T}_{C O}$ & $214.4(2.11)$ & $214.0(2.54)$ & $215.3(1.97)$ & $212.4(1.82)$ \\
$\bar{H}_{C P}$ & $17.7(0.09)$ & $17.4(0.06)$ & $17.2(0.10)$ & $17.5(0.10)$ \\
$\bar{H}_{\theta M}$ & $14.4(0.12)$ & $14.2(0.12)$ & $15.9(0.25)$ & $15.9(0.26)$ \\
$\bar{H}_{L R}$ & $16.2(0.03)$ & $15.9(0.04)$ & $16.6(0.08)$ & $16.7(0.15)$ \\
$\bar{H}_{C O}$ & $13.9(0.30)$ & $14.5(0.30)$ & $13.7(0.28)$ & $14.1(0.24)$ \\
\hline
\end{tabular}

number to depict the day-to-day variations as shown in Fig. 3. The cold point tropopause altitude $\left(H_{C P}\right)$ is at a higher level compared to the other tropopause altitudes. The lapse rate tropopause altitude $\left(H_{L R}\right)$ is closest to the $H_{C P}$. The altitudes of the lapse rate (potential temperature) minimum tropopause $\left(H_{\theta M}\right)$ and the convective outflow tropopause $\left(H_{C O}\right)$ are lower than $H_{C P}$ and $H_{L R}$ and are characterized by large day-to-day fluctuations. The $H_{C P}$ also shows fluctuations but not as large as $H_{C O}$ and $H_{\theta M}$.

The seasonal average values of the different tropopause altitudes and temperatures are shown in Table 1. The seasonal averages are represented by overbars on the respective parameters. The $\bar{H}_{C O}$ values in the table are different from those from Fig. 3 because $\bar{H}_{C O}$ are obtained by averaging the daily $H_{C O}$ values, whereas Fig. 3 represents the average profile of $D$ over the respective season. As noted earlier, data corresponding to strong convection events (which were of very infrequent occurrence during the period of observations) are not included in obtaining the different tropopause altitudes and temperatures. So, the seasonal averages shown represent averages not affected by strong convection events.

$\bar{H}_{C P}$ and $\bar{H}_{C O}$ are lowest in summer compared to winter, whereas for $\bar{H}_{\theta M}$ and $\bar{H}_{L R}$, lowest values occur in winter 2000 and the summer values are high. It is seen that the $\bar{H}_{C O}$ is lowest in summer 2001. $\bar{T}_{C O}$ is greater compared to the other three tropopause temperatures, as expected because of its lower altitude. The variability of $\bar{T}_{C O}$ and $\bar{H}_{C O}$ with season is quite low, compared to the other three. It is interesting to note that the variability of $\bar{H}_{C P}$ with season is quite low whereas $\bar{T}_{C P}$ shows significant variability. The coldest tropopause occurred in winter 2002, as seen for all the four tropopause temperatures. The temperatures are quite low in summer and are lower compared to winter of 1999 and 2000. Global analysis of tropical tropopause characteristics (considering cold point tropopause) revealed a colder tropopause in Northern Hemisphere winter and Indian summer monsoon and higher altitude for the tropopause in winter (Highwood 

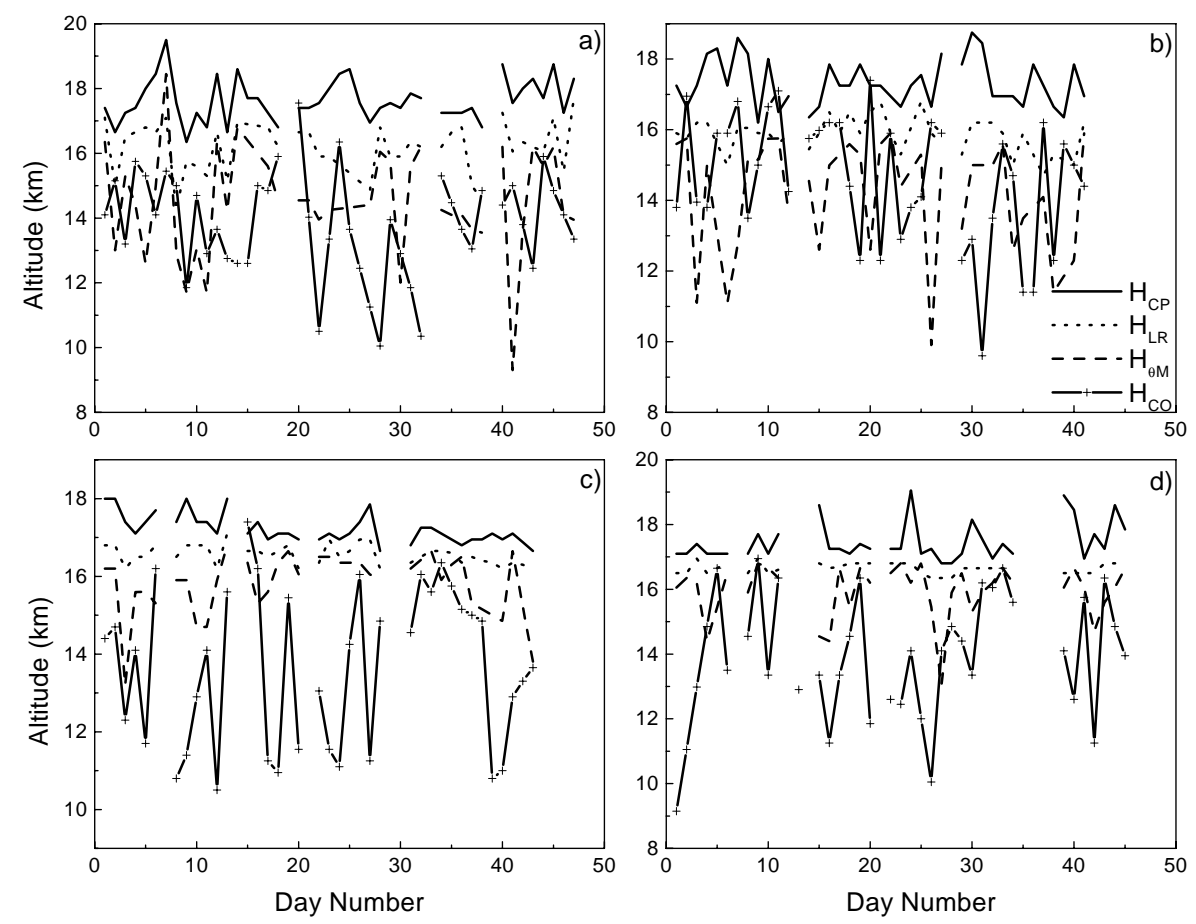

Fig. 3. Day-to-day variations of tropopause altitudes $H_{C P}, H_{L R}, H_{\theta M}$, and $H_{C O}$ for (a) winter 1999, (b) winter 2000, (c) summer 2001 and (d) winter 2002.

and Hoskins, 1998). The results presented above are in general agreement, especially for the cold point and convective tropopauses.

With a view to quantify the association, if any, between the different tropopauses, correlation coefficients are obtained between different pairs of tropopause parameters using their daily values for the four seasons and are tabulated in Table 2. Significant correlation coefficients at $P=0.1$ level (Fisher, 1970) are indicated by an asterisk mark. The $H_{L R}$ and $H_{C P}$ are positively correlated in all the seasons with significant coefficients, except in winter 2000. $H_{L R}$ and $H_{C O}$ are positively correlated with significant coefficients in summer 2001 and winter 2002, as are also $H_{\theta M}$ and $H_{C P}$ in winter 1999.

It is seen that except for $H_{L R}$ and $H_{C P}$, no other pair of tropopause altitudes show any consistency in correlation coefficients (and significant) for all the seasons. On the other hand, the correlation between the different pairs of temperatures are significantly positive and quite high in all the seasons, except in winter 2002 for the correlation involving $T_{C O}$. In particular, the correlation between $T_{L R}$ and $T_{C P}$ is very high in all the seasons and the correlation involving $T_{C O}$ is, in general, lower (though significant, except in winter 2002). The lapse rate tropopause and cold point tropopause are both governed by tropospheric (convective and radiative equilibrium) and lower stratospheric (radiative equilibrium) processes, whereas the tropopause corresponding to lapse rate minimum in potential temperature and the convective outflow tropopause are mainly governed by tropospheric upward flow. This could be the reason for the be-
Table 2. The correlation coefficient between the tropopause altitudes and temperatures using various definitions.

\begin{tabular}{lrrrr}
\hline & 1999 & 2000 & 2001 & 2002 \\
& Winter & Winter & Summer & Winter \\
\hline$H_{\theta M} \times H_{C O}$ & -0.10 & -0.01 & 0.15 & 0.11 \\
$H_{C P} \times H_{C O}$ & 0.13 & -0.10 & 0.01 & -0.10 \\
$H_{L R} \times H_{C O}$ & 0.13 & -0.04 & $0.35^{*}$ & $0.28^{*}$ \\
$H_{\theta M} \times H_{C P}$ & $0.50^{*}$ & 0.10 & 0.06 & 0.05 \\
$H_{L R} \times H_{C P}$ & $0.38^{*}$ & 0.20 & $0.66^{*}$ & 0.25 \\
$H_{\theta M} \times H_{L R}$ & 0.02 & $0.32^{*}$ & $0.39^{*}$ & -0.08 \\
& & & & \\
$T_{\theta M} \times T_{C O}$ & $0.33^{*}$ & $0.48^{*}$ & $0.51^{*}$ & 0.19 \\
$T_{C P} \times T_{C O}$ & $0.44^{*}$ & $0.60^{*}$ & $0.56^{*}$ & -0.01 \\
$T_{L R} \times T_{C O}$ & $0.54^{*}$ & $0.57^{*}$ & $0.59^{*}$ & -0.05 \\
$T_{\theta M} \times T_{C P}$ & $0.67^{*}$ & $0.72^{*}$ & $0.81^{*}$ & $0.58^{*}$ \\
$T_{L R} \times T_{C P}$ & $0.74^{*}$ & $0.98^{*}$ & $0.99^{*}$ & $0.78^{*}$ \\
$T_{\theta M} \times T_{L R}$ & $0.69^{*}$ & $0.73^{*}$ & $0.81^{*}$ & $0.55^{*}$ \\
& & & & \\
$T_{C P} \times H_{C P}$ & $-0.37^{*}$ & $-0.27^{*}$ & $-0.37^{*}$ & $-0.27^{*}$ \\
$T_{L R} \times H_{L R}$ & $-0.58^{*}$ & $-0.21^{*}$ & $-0.47^{*}$ & $-0.41^{*}$ \\
$T_{\theta M} \times H_{\theta M}$ & $-0.70^{*}$ & $-0.73^{*}$ & $-0.69^{*}$ & $-0.80^{*}$ \\
$T_{C O} \times H_{C O}$ & $-0.79^{*}$ & $-0.75^{*}$ & $-0.80^{*}$ & $-0.65^{*}$ \\
\hline
\end{tabular}

havior of the observed correlation coefficients. Recently, it has been suggested that the cold point tropopause is more of a stratospheric feature than of convection owing its existence 
to the onset near $100 \mathrm{hPa}$ of the photochemical production of ozone (Thuburn and Craig, 2002). It may be noted here that Gettelman and Forster (2002) reported that convective activity is not strongly correlated with the cold point tropopause temperature.

It is seen that the correlation coefficients between the tropopause altitude and temperature are negative and significant. Interestingly, these correlations are higher for the convective outflow and lapse rate minimum tropopauses than for the other two. When adiabatic conditions prevail, a lower altitude (higher pressure) would be associated with higher temperature and vice versa. This would be the condition for $T_{C O}\left(H_{C O}\right)$ and $T_{\theta M}$ and $\left(H_{\theta M}\right)$. The strong, negative correlations between $T_{C O}$ and $H_{C O}$, and $T_{\theta M}$ and $H_{\theta M}$ are in accordance with this. Diabatic processes are expected to take place above the top of the convection level, affecting $T_{C P}$ (and $H_{C P}$ ) and $T_{L R}$ (and $H_{L R}$ ). Thus, the negative correlation between $T_{C P}$ and $H_{C P}$ (and $T_{L R}$ and $H_{L R}$ ) may not be as strong as that between $T_{C O}$ and $H_{C O}$ (and $T_{\theta M}$ and $H_{\theta M}$ ), as observed.

\section{Conclusions}

The following are the main conclusions of the present study.

1. It is demonstrated that from the MST radar data of vertical wind, useful altitude profiles of horizontal divergence can be derived to obtain the level of convective outflow.

2. It is found that the convective outflow is stronger and occurs at a lower altitude in summer than in winter, where convective outflow occurs even in the lower stratosphere.

3. The altitudes of convective outflow tropopause and the lapse rate $(\theta)$ minimum tropopause show large day-today variation compared to those of lapse rate and cold point tropopauses.

4. The different tropopause temperatures are well correlated with each other. In general, seasonal tropopause is colder in winter compared to summer. However, the correlations between the temperature at the top of the convection and other tropopause temperatures are generally found to be low.

5. The tropopause temperature and altitude are negatively correlated on a day-to-day basis. The correlation is particularly strong between $T_{C O}$ and $H_{C O}$ (and $T_{\theta M}$ and $\left.H_{\theta M}\right)$.

Acknowledgements. The National MST Radar Facility (NMRF) is an autonomous Facility under Department of Space (DOS) with partial support from Council of Scientific and Industrial Research (CSIR). The authors are thankful to the technical and scientific staff of NMRF for their dedicated efforts in conducting the experiments. Most of the work reported in this paper was done under the Emeritus Scientist Scheme (CSIR) of B. V. Krishna Murthy. The authors express their thanks to the reviewers for their helpful suggestions and comments.

Topical Editor U.-P. Hoppe thanks a referee for his/her help in evaluating this paper.

\section{References}

Fisher, R. A.: Statistical methods for research workers, Oliver and Boyd, 177-249, 1970.

Gage, K. S., Ecklund, W. L., Riddle, A. C., and Balsley, B. B.: Objective tropopause height determination using low resolution VHF radar observations, J. Atmos. Oceanic. Technol., 3, 248254, 1986.

Gettelman, A. and Forster, P. M.: Definition and climatology of the tropical tropopause layer, J. Meteorol. Soc. Japan, 80:4B, 911924, 2002.

Gettelman, A., Salby, M. L., and Sassi, F.: The distribution and influence of convection in the tropical tropopause region, J. Geophys. Res., 107:D10, doi:10.1029/2001JD001 048, 2002.

Hartman, D. L. and Larson, K.: An important constraint on tropical cloud-climate feedback, Geophys. Res. Lett., 29, doi:10.1029/2002GL015 835, 2002.

Highwood, E. J. and Hoskins, B. J.: The tropical tropopause, Quart. J. Roy. Meteorol. Soc., 124, 1579-1604, 1998.

Holton, J. R., Haynes, P. H., McIntyre, M. E., Douglass, A. R., Rood, R. B., and Pfister, L.: Stratosphere-troposphere exchange, Rev. Geophys., 33, 403-439, 1995.

Jain, A. R., Rao, Y. J., Rao, P. B., Viswanathan, G., Damle, S. H., Balamuralidhar, P., and Kulkarni, A.: Preliminary observations using ST mode of the Indian MST radar: Detecting signature of the tropopause, J. Atmos. Terr. Phys., 56, 1157-1162, 1994.

Kirk-Davidoff, D. B., Hintsa, E. J., Anderson, J., and Keith, D. W. The effect of climate change on ozone depletion through changes in stratospheric water vapour, Nature, 402, 399-401, 1999.

Krishna Murthy, B. V., Satheesan, K., Parameswaran, K., Sasi, M. N., Ramkumar, G., Kumar, Y. B., Raghunath, K., and Krishniah, M.: Equatorial waves in temperature in the altitude range 4 to 70 km, Quart. J. Roy. Meteorol. Soc., 128, 819-837, 2002.

Mapes, B. E. and Houze, J. R. A.: An integrated view of the Australian monsoon and its mesoscale convective systems, II, Quart. J. Roy. Meteorol. Soc., 119, 733-754, 1993.

Mapes, B. E. and Houze, J. R. A.: Diabatic divergence profiles in tropical mesoscale convective systems, J. Atmos. Sci., 52, 1807 1828, 1995.

Mohan, K., Rao, D. N., Rao, T. N., and Raghavan, S.: Estimation of temperature and humidity from MST radar observations, Ann. Geophys., 19, 855-861, 2001,

SRef-ID: 1432-0576/ag/2001-19-855.

Rao, P. B., Jain, A. R., Balamuralidhar, P., Damle, S. H., and Viswanathan, G.: Indian MST radar 1. System description and sample vector wind measurements in ST mode, Radio Sci., 30, 1125-1138, 1995.

Reid, G. C. and Gage, K. S.: On the annual variation in height of the tropical tropopause, J. Atmos. Sci., 38, 1928-1938, 1981.

Reid, G. C. and Gage, K. S.: The tropocal tropopause over western Pacific: Wave driving, convection, and the annual cycle, J. Geophys. Res., 101, 21 233-21 241, 1996.

Revathy, K., Nayar, S. R. P., and Krishna Murthy, B. V.: Deduction of temperature profile from MST radar observations of vertical wind, Geophys. Res. Lett., 23, 285-288, 1996. 
Revathy, K., Nayar, S. R. P., and Krishna Murthy, B. V.: Troposphere and lower stratosphere temperature profile and its evolution from MST radar observations, in: STEP Handbook, (Ed.) Edwards, B., SCOSTEP Secretariat, University of Illionis, Ill. USA, 285-288, 1998a.

Revathy, K., Nayar, S. R. P., and Krishna Murthy, B. V.: Estimation of error in the determination of temperature using MST radar, Ind. J. Radio Space Phys., 27, 241-243, 1998b.

Revathy, K., Nayar, S. R. P., and Krishna Murthy, B. V.: Diurnal variation of tropospheric temperature at a tropical station, Ann. Geophys., 19, 1001-1005, 2001,

SRef-ID: 1432-0576/ag/2001-19-1001.
Salby, M., Sassi, F., Callaghan, P., Read, W., and Pumphrey, H.: Fluctuations of cloud, humidity and theramal structure near the tropical tropopause, J. Climate, 16, 3428-3446, 2003.

Selkirk, H. C.: The tropopause cold trap during STEP/AMEX 1987, J. Geophys. Res., 98, 8591-8610, 1993.

Sherwood, S. C., Horinouchi, T., and Zelenik, H. A.: Convective impact on temperatures observed near the tropical tropopause, J. Atmos. Sci., 60, 1847-1856, 2003.

Thuburn, J. and Craig, C. G.: On the temperature structure of the tropical substratosphere, J. Geophys. Res., 107, doi:10.1029/2001JD00 048, 2002. 